\title{
ANALISIS KELENGKAPAN INFORMED CONSENT PASIEN PRA OPERASI KATARAK DI RS. KHUSUS MATA SMEC MEDAN TAHUN 2018
}

\author{
1. Esraida Simanjuntak; ${ }^{2 .}$ Sara Agatha Wismona \\ 1. Dosen APIKES Imelda, Jalan Bilal Nomor 52 Medan; ${ }^{2}$ APIKES Imelda \\ E-mail: ${ }^{1 .}$ esraida.borjun@gmail.com
}

\begin{abstract}
ABSTRAK
Rekam medis merupakan berkas yang berisikan catatan dan dokumen tentang identitas, pemeriksaan, pengobatan, tindakan, dan pelayanan lain yang telah diberikan kepada pasien. Tujuan dari penelitian ini adalah untuk mengetahui faktor - faktor apa saja yang mempengarui kejelasan informasi medis yang akan diterima oleh pasien pra operasi katarak. Jenis penelitian ini adalah kuantitatif penelitian yang hanya menggambarkan keadaan objek, tidak ada maksud untuk menggeneralisasi hasilnya. Waktu penelitian ini dilakukan pada bulan Juni-Juli 2018 di RS. Khusus Mata SMEC Medan Tahun 2018. Dalam melakukan penelitian ini, peneliti mengambil populasi sebanyak 55 berkas. Berdasarkan hasil penelitian yang dilakukan di RS. Khusus Mata SMEC Medan pemberian informasi medis dilakukan sepenuhnya oleh petugas yang berwenang. Tetapi dalam pemberian informasi medis beberapa petugas tidak menjelaskan secara keseluruhan seperti hanya memberikan 9 informasi medis dari 11 informasi medis yang seharusnya diberikan kepada pasien. Kesimpulannya adalah kelengkapan pengisian lembar informed consent pada berkas rekam medis di RS. Khusus Mata SMEC sesuai dengan hasil penelitian yaitu sebanyak $58 \%$ yang lengkap, dan yang tidak lengkap sebanyak $42 \%$. Sebaiknya petugas dapat memberikan informasi sesuai dengan SOP yang telah di tetapkan oleh RS. Khusus Mata SMEC Medan agar para pasien akan lebih mendapatkan kejelasan informasi medis yang mereka perlukan.
\end{abstract}

Kata Kunci: Rekam Medis, Kelengkapan, Informed Consent

\section{PENDAHULUAN}

Rumah sakit adalah institusi pelayanan kesehatan yang menyelenggarakan pelayan an kesehatan perorangan secara paripurna yang menyediakan pelayanan rawat inap, rawat jalan, dan gawat darurat. Berdasarkan pelayanannya rumah sakit terbagi atas 2 yaitu rumah sakit umum dan rumah sakit khusus, Rumah Sakit Umum adalah rumah sakit yang memberikan pelayanan kesehata $\mathrm{n}$ pada semua bidang dan jenis penyakit. Sedangkan rumah sakit khusus adalah rumah sakit yang memberikan pelayanan utama pada satu bidang atau satu jenis penyakit tertentu berdasarkan disiplin ilmu, golongan umur, organ, jenis penyakit atau kekhususan lainnya (PMK 56 Tahun 2014).

Penyelenggara upaya kesehatan di rumah sakit tidak lepas dari peran serta rekam medis di setiap unit pelayanan kesehatan. Berdasarkan PERMENKES No. 269/PER/III/2008 Rekam Medis adalah ber kas berisi catatan dan dokumen tentang pasien yang berisi identitas, pemeriksaan, $p$ engobatan, tindakan medis lain pada sarana pelayanan kesehatan untuk rawat jalan, rawat inap baik dikelola pemerintah maupu $\mathrm{n}$ swasta. Yang bertanggung jawab dalam pengisian berkas rekam medis pasien adalah dokter dan perawat, akan memudahk an tenaga kesehatan lain seperti tenaga farmasi, tenaga gizi dan tenaga keteknisian medis, dalam memberikan tindakan medis atau terapi kepada pasien. Sebelum melakukan tindakan medis, pasien akan menerima informasi tindakan apa saja yang akan dilakukan. Akan tetapi, informasi pela yanan kesehatan yang diberikan oleh Dokte $r$ (petugas) sering sekali kurang jelas dan 
tidak dapat dimengerti oleh pasien sehingga keputusan pasien atau keluarganya untuk memperoleh pelayanan kesehatan juga kurang tepat, mungkin saja berdampak buruk pada pelayanan kesehatan yang diperolehnya seperti dapat terjadi malpraktek, dan kesalahan pengobatan. Oleh karena itu perlu kiranya kita mengetahui apa itu informed concent.

Informed concent yaitu persetujuan tindakan kedokteran yang diberikan kepada pasien atau keluarga pasien setelah mendap atkan penjelasan secara lengkap mengenai $t$ indakan kedokteran dan kedokteran gigi yang akan dilakukan terhadap pasien (Permenkes No.290 Tahun 2008). Untuk jenis tindakan medis ringan, persetujuan dari pasien dapat diwujudkan secara lisan at au dengan menggerakkan alat tubuh seperti mengangguk untuk menunjukkan bahwa pasien setuju. Untuk tindakan medis yang lebih besar atau beresiko, persetujuan dilakukan dengan menandatangani formulir persetujuan tindakan medis. Dalam proses tersebut pasien berhak mendapat informasi yang cukup mengenai rencana tindakan medis yang akan diterimanya.Informasi tersebut akan diberikan oleh dokter yang akan melakukan tindakan atau petugas medis lain yang diberi wewenang.

Informasi/keterangan yang wajib diber ikan sebelum suatu tindakan kedokteran dilaksanakan adalah diagnosa yang telah ditegakkan;sifat dan luasnya tindakan yang akan dilakukan;manfaat dan urgensinya dilakukan tindakan tersebut;resiko-resiko dan komplikasi yang mungkin terjadi daripa da tindakan kedokteran tersebut; alternatif cara pengobatan yang lain, Prakiraan biaya yang menyangkut tindakan kedokteran tersebut.

Berdasarkan survei awal di RS Khusus Mata SMEC Medan, pemberia informasi kesehatan dilaksanakan oleh Dokter Penanggung Jawab Pasien (DPJP) dan perawat yang merawat pasien, sesuai dengan Standar Prosedur Operasional (SPO) yang telah di tetapkan oleh rumah sakit SMEC. Terdapat 11 jenis informasi kesehatan yang akan disampaikan kepada pasien atau keluarga pasien pra operasi katarak yaitu diagnosis; dasar diagnosis; tin dakan kedokteran; indikasi tindakan; tata ca ra tipe anastesi/sedusi, uraian singkat prosedur dan tahapan yang penting; tujuan; risiko; komplikasi; prognosis; alternatif dan resiko; hal lain yang akan dilakukan untuk menyelamatkan pasien. Namun, dalam 11 informasi tersebut hanya 9 informasi yang diisi di dalam formulir pemberian informasi Berdasarkan permasalahan diatas penu lis tertarik untuk melakukan penelitian dengan judul "Analisis kelengkapan Inform ed Consent pada pasien pra operasi katarak di RS. Khusus Mata SMEC Medan tahun 2018".

\section{Perumusan Masalah}

Berdasarkan latar belakang di atas, maka penulis merumuskan masalah dalam penelitian ini adalah bagaimana kelengkapa $\mathrm{n}$ pemberian informasi medis di lembar informed consent pada pasien pra operasi katarak di RS Khusus Mata SMEC Medan?

\section{Tujuan Penelitian}

Adapun tujuan dari penelitian ini adalah untuk mengetahui kelengkapan pemberian informasi medis di lembar informed consent pada pasien pra operasi katarak di RS Khusus Mata SMEC Medan.

\section{METODE}

\section{Jenis Penelitian}

Jenis Penelitian yang digunakan dalam penelitian ini adalah kuantitatif yang bertuj uan untuk mengetahui kelengkapan informe $d$ consent pada pasien pra operasi katarak di RS Khusus Mata SMEC Medan. Menurut Sulistyaningsih (2011), penelitian deskriptif adalah penelitian yang hanya menggambar kan keadaan objek, tidak ada maksud untuk menggeneralisasi hasilnya, melakukan anali sis kualitatif dan tanpa menguji hipotesis.

\section{HASIL DAN PEMBAHASAN}

Dari hasil penelitian tentang analisis kelengkapan informed consent pada pasien pra operasi katarak di RS. Khusus Mata SMEC Medan tahun 2018 data diperoleh dari 55 berkas rekam medis, dapat dilihat pada tabel di bawah ini: 
Tabel 1. Distribusi Kelengkapan Informent Consent Pada Pasien Pra Operasi Katarak Di RS. Khusus Mata SMEC Medan Tahun 2018.

\begin{tabular}{llrrrr}
\hline No & $\begin{array}{c}\text { Kelengkapan } \\
\text { informed } \\
\text { consent }\end{array}$ & \multicolumn{2}{c}{ Lengkap } & \multicolumn{2}{c}{$\begin{array}{c}\text { Tidak } \\
\text { Lengkap }\end{array}$} \\
\cline { 2 - 6 } & & f & \% & f & \% \\
\hline 1 & Diagnosis & 55 & 100 & - & - \\
\hline 2 & Dasar diagnosis & 55 & 100 & - & - \\
\hline 3 & $\begin{array}{l}\text { Tindakan } \\
\text { kedokteran }\end{array}$ & 55 & 100 & - & - \\
\hline 4 & Indikasi tindakan & 55 & 100 & - & - \\
\hline 5 & Tipe anestesi & 55 & 100 & - & - \\
\hline 6 & Tujuan & 55 & 100 & - & - \\
\hline 7 & Risiko & 55 & 100 & - & - \\
\hline 8 & Komplikasi & 55 & 100 & - & - \\
\hline 9 & Prognosis & 50 & 90,9 & 5 & 9,1 \\
\hline 10 & $\begin{array}{l}\text { Alternatif \& } \\
\text { resiko }\end{array}$ & 32 & 58,2 & 23 & 41,8 \\
\hline 11 & Hal lain untuk & 32 & 58,2 & 23 & 41,8 \\
& $\begin{array}{l}\text { menyelamatkan } \\
\text { pasien }\end{array}$ & & & & \\
\hline & Tabel di atas & & & & \\
\hline
\end{tabular}

Tabel di atas dapat kita ketahui bahwa untuk kelengkapan informed consent masih ditemukan yang tidak lengkap pada prognosis sebanyak 9,1\% , Alternatif resiko sebanyak 41,8 \% dan Hal lain untuk menyelamatkan pasien sebanyak 41,8\%. Kelengkapan pengisian lembar informed consent pada berkas rekam medis di RS. Khusus Mata SMEC sesuai dengan hasil penelitian yaitu sebanyak $58 \%$ yang lengkap, dan yang tidak lengkap sebanyak $42 \%$.

Berdasarkan Permenkes 290 tahun 2008 pasal 9 ayat 1 " Penjelasan informasi medis harus diberikan secara lengkap dengan bahasa yang mudah dimengerti atau cara lain yang bertujuan untuk mempermud ah pemahaman"Dari hasil penelitian yang dilakukan tentang kelengkapan Informed Consent di RS. Khusus Mata SMEC untuk kelengkapan informed consent pada bagian pengisian Diagnosa, Dasar Diagnosis, Tindakan Kedokteran, Indikasi Tindakan, Tipe Anestesi, Tujuan, Risiko, Komplikasi, sudah 100\% lengkap. Sedangkan untuk pengisian Prognosis masih ditemukan yang tidak lengkap sebanyak $9,1 \%$, Alternatif dan resiko sebanyak 41,8\% dan Hal lain untuk menyelamatkan pasien sebanyak $41,8 \%$.

\section{KESIMPULAN}

Kesimpulan dari penelitian ini adalah kelengkapan pengisian lembar informed consent pada berkas rekam medis di RS. Khusus Mata SMEC sesuai dengan hasil penelitian yaitu sebanyak 58\% yang lengkap, dan yang tidak lengkap sebanyak $42 \%$.

\section{SARAN}

Sebaiknya petugas dapat memberikan informasi sesuai dengan SOP yang telah di tetapkan oleh RS. Khusus Mata SMEC Medan agar para pasien akan lebih mendapatkan kejelasan informasi medis yang mereka perlukan.

\section{DAFTAR PUSTAKA}

Hatta, G. (2008). Pedoman Managemen Informasi Kesehatan di Sarana Pelaya nan Kesehatan. Jakarta: UI-Press.

Iliyas, Sidarta. (2014). Ilmu Penyakit Mata Edisi 5. Jakarta: FKUI.

Permenkes No. 269/ MENKES / PER/ III /2008. (2008). Tentang Rekam Medis.J akarta: Departemen Kesehatan Republik Indonesia.

Permenkes No. 290 Tahun (2008). Tentang Persetujuan Tindakan Kedokteran. Jak arta: Departemen Kesehatan Republik Indonesia

PERMENKES No. 56 Tahun (2014). Tenta ng Klasifikasi dan Perizinan Rumah Sakit. Jakarta: Departemen Kesehatan Republik Indonesia

Rustianto, Ery. (2009). Etika Profesi Perekam Medis dan Informasi Kesehatan. Yogyakarta: Graha Ilmu.

Sulistyaningsih. (2011). Metodologi Penelit ian Kebidanan Kuantitatif Kualitatif. Yogyakarta: Graha Ilmu.

Undang-undang RI Nomor 29 tahun 2004. (2004). Tentang Praktik Kedokteran. Jakarta: DPR RI.

Undang-Undang RI Nomor 44 tahun 2009. (2009). Tentang Rumah Sakit. Jakarta: Departemen Kesehatan Republik Indo nesia. 